\title{
EL MODEL DE MISA
}

Antoni Roca Rosell

Antoni.Roca-Rosell@upc.edu

MISA, Thomas J. (2004) Leonardo to the Internet. Technology E Culture from the Renaissance to the Present, Baltimore-Londres, The John Hopkins University Press, 324 p. il.1., índex de noms propis i conceptes, ISBN 08018 7809-8 (paperback).

L'oferta de síntesis generals d'història de la tècnica no és gaire elevada i, malauradament, moltes de les que hi ha al mercat o bé han quedat desfasades pels estudis històrics o bé estan situades al marge de la historiografia. És, per consegüent, un fet molt destacable que hagi aparegut una nova síntesi, construïda sobre la historiografia més actual i que presenta perspectives molt suggestives. És el cas del darrer llibre de Thomas Misa, professor de l'Institut de Tecnologia d'Illinois, a Chicago. El títol podria induir a pensar que el llibre fa concessions al mercat, però, en realitat, si es tracta de concessions, estan molt ben resoltes. Thomas Misa dóna diferents cursos d'història i humanitats al seu Institut. La seva pàgina al web, on hi ha els programes dels cursos que imparteix, és molt instructiva, especialment, no cal dir-ho, per a professors d'història de la tècnica.

La primera aportació que apreciem en el llibre de Misa és la seva determinació de períodes cronològics, que correspon als capítols principals del seu llibre. És la següent:

1) Les tecnologies de Cort (1450-1600)

2) Tècniques del comerç (1588-1740)

3) Geografies de la indústria (1740-1851)

4) Instruments de l'Imperi (1840-1914)

5) Ciència i sistemes (1870-1930)

6) Materials del racionalisme (1900-1950)

7) Els mitjans de destrucció (1936-1990)

8) Cap a una cultura global (1970-2001)

Es pot veure que Misa recull els treballs dels seus antecessors, principalment Arnold Pacey, diverses obres del qual són mencionades al llarg del text. Fem ara un breu resum del que proposa Misa en cada una d'aquestes fases 
de la història moderna de la tècnica. Notem, abans de fer-ho, que les fases de Misa se sobreposen explícitament en el temps, cosa que respon al reconeixement que la història és, en realitat, contínua i que la historiografia necessita sobreposar-hi períodes. El punt de partida de Misa és l'època en la qual l'hegemonia fou la tècnica portada a terme sota la protecció dels prínceps i els reis. Itàlia en fou l'escenari principal. La característica d'aquesta tècnica és el fet d'apartar-se de les necessitats socials. Leonardo i els seus contemporanis oferiren sistemes de fortificació, màquines de guerra fantasioses, grans construccions en esglésies i monuments, però es mantingueren al marge de les tècniques agrícoles, de les de navegació o del tèxtil, per posar uns quants exemples de tècniques en les quals es fonamentava la vida social del Renaixement. Els exemples de Misa són italians, que són sens dubte molt representatius, però potser hauria estat rellevant incorporar la tècnica de Cort que es creà als regnes d'Espanya, llavors la principal potència mundial.

El període que Misa considera a continuació és el del món del comerç, aquesta vegada amb el centre de gravetat als Països Baixos. La xarxa internacional d'intercanvi que creà la república neerlandesa, anticipada per Espanya i Portugal, com Misa assenyala, creà unes noves condicions econòmiques a Europa i al món. És un sistema tècnic fonamentat en la navegació i en la generació de productes d'intercanvi, tant a partir de la creació d'una agricultura productiva i una indústria manufacturera als Països Baixos, com amb la comercialització de productes d'Orient. Aquest fou un dels orígens del capitalisme. Com a competidors dels Països Baixos, s'incorporaren al món del comerç els anglesos i els francesos. En el període següent, dedicat a la Revolució Industrial, Misa ens parla de "geografies" de la indústria, perquè assenyala que la Revolució Industrial es desenvolupà en termes regionals. Posa el cas d'Anglaterra, on el sistema de fàbrica correspon al model d'industrialització de Manchester, a partir del tèxtil de cotó, però que convisqué amb la conca minera i manufacturera d'acer de Sheffield i amb el desenvolupament de la ciutat de Londres; aquesta basà la seva indústria tant en el port i la construcció naval com en indústries fins ara poc tingudes en compte, com la cerversera. A Londres, cap al 1850, hi havia més obrers que a Manchester.

El període que Misa considera a continuació és el de l'imperialisme. Ara, altre cop, unes determinades tecnologies adquireixen protagonisme en relació amb l'estratègia de control i dominació de l'Imperi britànic i, en part, del francès i l'alemany. El ferrocarril, el telègraf i les armes automàtiques prenen una significació especial. Aquestes tecnologies, que tingueren un gran 
impacte en la societat europea i americana, s'implantaren a llocs com l'Índia a remolc dels interessos militars i d'explotació.

Ciència i sistemes és el període següent, en què es presenta l'entrada efectiva de la ciència com a força tecnològica i industrial. Això tingué lloc en la indústria elèctrica i en la química, principalment en els tints artificials i la fabricació de sosa càustica. La implicació de la ciència es donà en sistemes tècnics i industrials cada cop més complexos, dels quals el sistema d'electrificació n'és un exemple paradigmàtic. A més, això féu créixer la demanda d'ensenyament en general i d'ensenyament tècnic en particular.

Misa titula el període següent "Dels materials del modernisme", però jo m'he permès traduir-lo per "racionalisme", perquè és així com coneixem el moviment que culminà, per exemple, amb l'escola de la Bauhaus. L'ús dels nous materials i l'actualització de materials de construcció poc emprats abans (formigó, ferro, vidre i maons), tenint presents uns objectius socials de benestar per a la població. Hi destaquem la menció a l'arquitecta austríaca Grete Lihotzky, inventora de la cuina de Frankfurt, és a dir, l'habitació distribuïda de manera funcional per facilitar les feines de la cuina tal com la coneixem avui en dia.

El període següent és el dominat per la intervenció de l'exèrcit en el desenvolupament tecnològic, que Misa tanca amb la caiguda de la Unió Soviètica. D'una banda, Misa recorda que la construcció de la bomba atòmica no solament representà una mobilització de recursos de recerca, sinó que ho va fer més en el camp industrial. Dins del projecte Manhattan, el laboratori de Los Alamos no significava més del $5 \%$ del pressupost. D'altra banda, el suposat benefici de la demanda militar és posat en qüestió en alguns exemples, com ara el desenvolupament del transistor per als sistemes de control i comunicació de la Força Aèria dels Estats Units. La demanda de l'exèrcit fou tan gran que la companyia Bell, inventora de l'artefacte, endarrerí més de deu anys la seva aplicació a la telefonia. En el capítol de la globalització, trobareu la discussió de casos d'actualitat i en una perspectiva poc comuna. Misa parla de l'adaptació relativa de la gran cadena d'entrepans d'hamburguesa als diferents contextos culturals, que contrasta amb la seva identificació amb homogeneïtzació de l'alimentació. També parla del desenvolupament d'Internet, una tecnologia que s'ha estès molt més enllà del que havien previst.

Tot plegat ens ofereix una nova perspectiva de la història de la tecnologia en la societat, on es posa de manifest que és imprescindible tenir en compte el context històric per entendre la difusió i l'ús d'una determinada tecnologia o, més ben dit, d'un determinat sistema tecnològic. 